\title{
Centralized Education Management Information System for Tracking Student's Academic Progress in Tanzanian Secondary Schools
}

\author{
ANOLD S. NKATA \\ The Nelson Mandela African Institution of Science and Technology, P.O. Box 447, Arusha, Tanzania. \\ Arusha Technical College, P.O.Box 296, Arusha,Tanzania \\ Email: nkataa@nm-aist.ac.tz or anold.it2008@gmail.com \\ Dr. MUSSA A. DIDA \\ The Nelson Mandela African Institution of Science and Technology, P.O. Box 447, Arusha,Tanzania. \\ Email: mussa.ally@nm-aist.ac.tz
}

Received: 15 August 2019; Accepted: 11 September 2019; Published: 08 October 2019

\begin{abstract}
Application of Education Management Information System for administering school academic activities is widely recognized as an essential tool of improving quality of education for sustainable development. However, in developing countries including Tanzania, most secondary schools use manual system for collecting, storing and disseminating education information. The Manual system limits schools to have accurately, timely and reliable dissemination of education information. Moreover, when parents want to monitor student's academic progress, the manual system requires them to visit schools physically and sometimes to wait until the end of the terminal and annual examination to get student academic report. Social and economic activities are one of the factors which limit parents to monitor student's academic progress effectively. Poor parental involvement for monitoring and tracking student's academic progress leads to poor student academic achievement. To address the solution, the study used structured interview and questionnaires to collect data from secondary schools education stakeholder. The collected data was analyzed using Pandas Python data analysis package. Findings from the study revealed that, poor student academic achievement in Tanzanian secondary schools is being caused by poor parental involvement in monitoring and tracking student's academic progress. However, the study developed and implemented a centralized Education Management Information System for enhancing parental involvement in monitoring and tracking student's academic progress. The significance of this study was to enhance parental involvement for student academic achievement by improving delivery of quality education for sustainable development.
\end{abstract}

Index Terms-EMIS, parental involvement, student's academic achievement

\section{INTRODUCTION}

The term parental involvements for student's academic achievement is not a new concept in the field of education [1].The term is commonly used to mean different things at a different context [2]. According to Mississippi Department of Education [3] parental involvement is defined as the process of parents to discuss with teachers about student's academic progress, achievement and to engage them with school academic activities. In this study, the term parental involvement is specifically used to mean a process of involving parents with school academic activities and in monitoring and tracking student's academic progress. Findings from previous researchers shows that, parental involvement plays a significance role of improving student's academic achievement $[4,8]$.

Despite of the significance of parental involvement for the student academic achievement, the practice of enhancing parental involvement remain a challenge to secondary schools $[7,9,10]$. In most secondary schools, teachers end up getting a poor response from parents when they want to engage them with school academic activities and on student's academic progress. Different methods and strategies such as school to use social media, phone call and text message to enhance parental involvement through communication have been suggested by previous scholars $[2,5,7,8]$. However, the suggested solutions are not cost effective solution for teachers and secondary schools belonging to developing countries including Tanzania simply because it adds them with other financial costs. Moreover, due to poor ICT infrastructures available in schools, budget constraints of running schools academic activities and an individual economy of teachers, this solution is not affordable for Tanzanian secondary schools $[11,12]$ 
To improve quality of education for sustainable development, Tanzanian secondary schools have to implement a Centralized Education Management Information System (EMIS) for collecting storing and disseminating school academic information. Parents has to login to the system and view student academic report. Moreover, parents should be notified the student academic progress by E-mail and Short Message Service (SMS) generated from the system.

The best approach of enhancing parental involvement with cost effective solution is to use a web based education system architecture which does not require schools to own a powerfully server computer, public IP address and to employ IT professional system administrator.

\section{RELATED WORKS}

To address the problem of parental involvement and improve quality of education for sustainable development, the study reviewed various theories and concepts of various education scholars and findings of previous studies.

\section{A. Review of theories and concepts of various scholars}

Various theories and concepts of previous researcher highlights the significance of parental involvement for student's academic achievement [13-17]. Past scholars in this field [1,13,17-19] positively knowledge the practice of enhancing parental involvement by applying science, innovation and technology (STI). Teachers and parents both have positive concepts and perception of enhancing parental involvement for student's academic achievement [16].

According to the study conducted by Akter in Bangladesh [20], it reveals that parental involvement of monitoring student's academic progress is specifically a job meant for female than a male in a family. Moreover, in developing countries, including Tanzania, a visit to school for academic purposes to most parents is unusual [21]. Due to various theories and concepts, it is clear that, most schools do not have a proper digital tool and parental involvement policy for student's academic achievement.

\section{B. Review of previous research findings}

Similar study was conducted by Olmstead [22] at California to explore parental involvement using digital technology did not come up with any tangible output of which digital technology best suit enhancement of parental involvement. However, the study ended by recommending schools to formulate parental involvement policies for student's academic achievement.

A study conducted by Jason Kemp [23] reveals that, application of social networks like face book and twitter can improve communication between teacher and parents for student's academic achievement. Despite of these findings, the technology if not cost effective solution for the users simply because the technology require both users to own a smart phone and to have internet connection. Moreover, suggested technological solution, is not a reliable platform for developing countries especially for parents of rural areas due to their family income.

Limin [10] conducted a similar study and identified the use of school website to improve parental involvement. Despite of the findings, Kraft and Dougherty [24], identified schools website as commonly tool used for marketing school goods. In respect to this contradiction, the school website is not an effective tool for enhancing parental involvement for student's academic achievement

In Taiwan [25], enhancement of communication between teacher and parent for student academic matters is done by using Short Message Service (SMS) and Smart device message. However, this platform cannot be convenient tool for Tanzania secondary schools; simply because it can lead to another cost for teachers to own a smart phone and their phone to have enough bandwidth.

\section{MAterials AND Methods}

\section{A. Study area}

The study was conducted in secondary schools of Arusha region, a northern of Tanzania from March $4^{\text {th }}$ 2019 to May 29 ${ }^{\text {th }} 2019$. The prevailing social and economic activities of Arusha citizens is animal keeping [26]. The region has two hundred thirty six secondary schools of which one hundred and eighty are public secondary schools and fifty six are private secondary schools.

\section{B. Ethical consideration and demographic information}

This study considered all ethical issues and demographic information in carrying out research processes. Data protection and privacy of respondents were taken into ethical consideration for the significance of the study and for the sustainable development. The system was developed and implemented by considering all security controls such as data confidentiality, data integrity, nonrepudiation and system availability. However, the EMIS is secured with system log and activity $\log$.

\section{Research methodology}

The researcher adopted different methods and techniques to ensure validity and reliability of the research findings. The flow chart below describes various phases used for conducting this study.

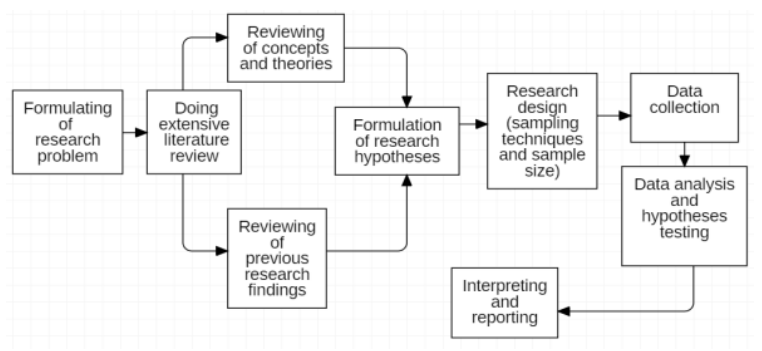

Fig.1. Research phases used by the researcher 


\section{Sampling techniques}

The researcher used purposely sampling techniques to select secondary schools of rural areas and urban area for the purpose of collecting data from students, teachers and parents. A total of fifty secondary schools were surveyed of which twenty five secondary schools were from urban area and another twenty five secondary schools were from rural areas.

A simple random sampling technique was used to design a sample from the entire population of the respective school. In this case, each student, teacher and parents in the school was having equal chance of being selected for data collection. Moreover, the researcher surveyed one office of Districts Education Officer (DEO) and Ward Education Coordinator (WEC) as an education policy maker for validity and collecting more data. Demographic factors such as geographical location and similarity of their duties and core function of their offices leads to choose one office of Districts Education Officer (DEO) and another one office of Ward Education Coordinator (WEC).

\section{E. Methods of data collection}

The study used structured interview and questionnaire to collect data from education stakeholders of Tanzanian secondary schools. Questionnaire was distributed to students, teachers and parents. Interview guide questions were used to collected data from education policy makers, school academic teachers and school discipline teacher.

\section{F. Sample size}

To obtain a sample size for data collection the study used a formula by (Smith, 2013), see equation (1) below:

$$
n=\frac{z^{2}}{m e^{2}} p(1-p)
$$

where $n$ represents a sample size of an infinite population, $z$ stands for Z-score in this case the study used 1.645 for the confidence level of $90 \%$, me stands for margin error equal to $60 \%, p$ represents population proportion of $40 \%$. Therefore from the computation below:

$$
n=\frac{1.645^{2}}{(0.06)^{2}}(0.4(1-0.4)=180
$$

Then sample size becomes one hundred and eight.

\section{G. Data analysis and interpretation}

The study used Pandas, a Python data analysis package to analyze data collected. Functional and non-functional requirements of the system were collected and analyzed based on software engineering techniques [27].

\section{H. System development tools}

The centralized Education Management Information System (EMIS) for tracking student's academic progress was developed and implemented using server side scripting language and client side scripting languages. Web programing languages which are HTML, CSS, JavaScript and PHP were used to develop EMIS. MySQL database management systems were used to design database system. The system is compatible with all computer hardware and can operate into both windows and Linux operating system environments.

\section{System development methodology}

To ensure delivery of high quality systems with customer satisfaction the study adopted Agile system development methodology in developing and implementing centralized Education Management Information System. However, the study used six phases of Software Development Life Cycle (SDLC) to develop the systems. The following phases were adopted from software engineering: requirement gathering, analysis, design, implementation, training, operation and maintenance. Under Agile system development methodology, the study opted to use extreme programming methodology in order to speed up development processes and for ensuring delivery of high quality system with cost effective. Furthermore, the study employed iterative techniques so as to allow instant feedback from the users. The diagram below describes iterative techniques used to develop and implement EMIS

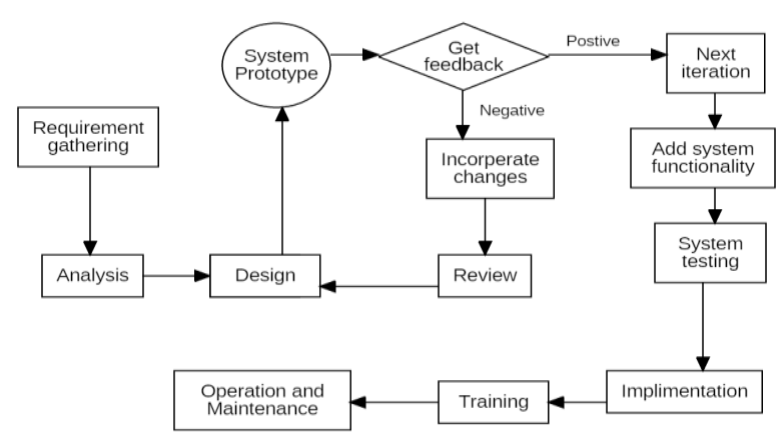

Fig.2. Iterative development methodology used to develop the system

\section{RESULTS}

A. Review of an existing system used by Tanzanian secondary schools for administering school academic activities

To identify and review various systems used by Tanzanian secondary schools to collect, store, process and disseminate education information, the researcher collected primary data from one hundred and three secondary schools teachers. In this respect, respondents were asked about what kind of systems does their school use to report student's academic progress and for administering school academic activities. From the data analysis, the study found that, $98 \%$ of secondary schools use manual system for reporting and administering school academic activities. While $2 \%$ use both manual and 
automated systems. Fig. 3 below illustrates findings of the data collected from teachers.

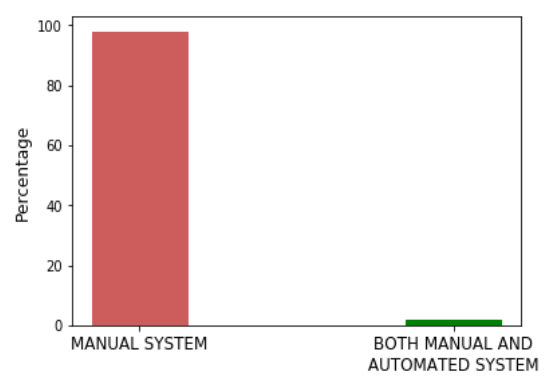

Fig.3. Systems used by Tanzanian secondary schools to administer academic activities.

B. Drawbacks of manual systems for enhancing parental involvement for tracking student's academic progress

The researcher asked question to one hundred seventy eight respondents in order to determine whether manual system enhance parental involvement in monitoring and tracking student's academic progress. From the data analysis, $93 \%$ of total respondents said manual system does not enhance parental involvement in monitoring and tracking student's academic progress. Only $2 \%$ of total respondents said the manual system enhance parental involvement in monitoring and tracking student's academic progress. While $5 \%$ of total respondents said they are not sure whether manual systems enhance parental involvement or not. Fig. 4 below illustrates findings of the primary data collected from teachers, student, parents and guardians.

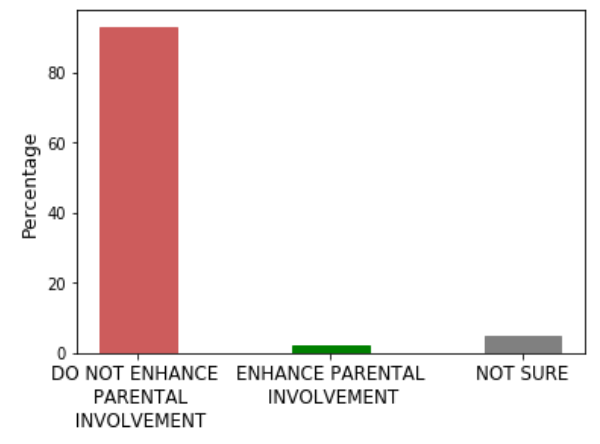

Fig.4. Enhancement of parental involvement due to the usage of manual systems

C. Views of education stakeholders whether digital technology can improve parental involvement for student's academic achievement

In order to get views and perception of various education stakeholders on the application of digital technology like centralized Education Management Information System for improving parental involvement in monitoring and tracking student's academic progress, the researcher collected primary data from one hundred and thirty education stakeholders. From the data analysis, $90 \%$ of total responded agreed that, application of digital technology like centralized Education Management Information System can improve parental involvement. While $10 \%$ of total responded disagree. Fig.5 below illustrates the findings of the data collected from teachers, parents, guardians, Districts Education Officer (DEO) and Ward Education Coordinator (WEC).

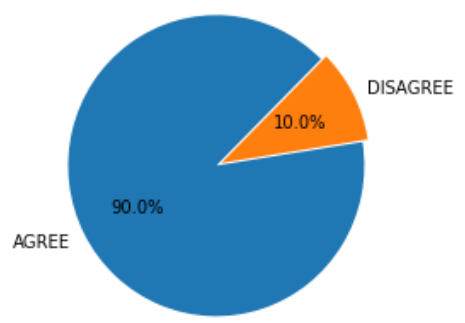

Fig.5. Views and perception of education stakeholders for using digital technology to improve parental involvement

D. Reason behind why most schools do not prefer to use web based education system for administering school academic activities.

Primary data was collected from teachers, Districts education Officer (DEO) and Ward Education Coordinator (WEC) to explain why most secondary schools do not prefer to use web based education systems for administering school academic activities. From the data analysis, $50 \%$ of the respondents said school do not prefer to use web based education system for administering school academic activities due to additional costs caused by the system. $30 \%$ of the respondents said schools lack ICT infrastructure for supporting web based system, while $20 \%$ of the total respondents said, because of computer illiteracy of teachers that's why school do not use web based system for administering school academic activities. Fig. 6 below illustrates the findings of the data analysis.

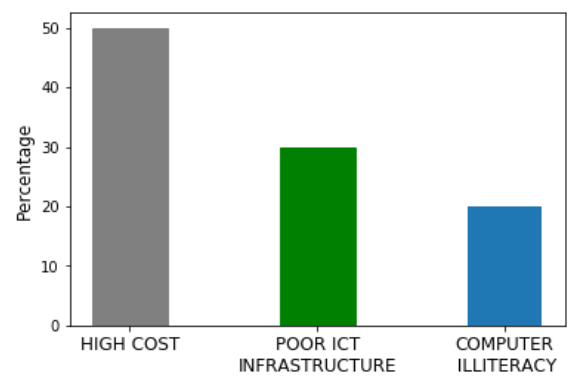

Fig.6. Reasons behind why most schools do not prefer to use web based education system

\section{E. Assessment of parental involvement in relation to gender}

The study used demographic information to assess parental involvement of male and female in monitoring and tracking student's academic progress. From the data analysis, the study found that, parental involvement of female in monitoring and tracking student's academic 
progress is higher than that of male. Fig.7 below presents findings of primary data collected from one hundred and eight respondents.

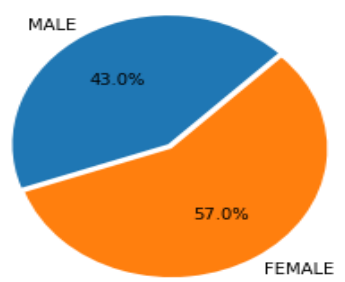

Fig.7. Comparison of parental involvement in relation to gender of male and female

\section{DISCUSSION}

Findings from the study reveals that, parental involvement for monitoring and tracking student's academic progress is being hindered with manual system used by Tanzanian secondary schools for reporting student's academic progress. Moreover, the manual system used by Tanzanian secondary schools to collect, store and disseminate education information do not support education policy makers in planning and budgeting education resources hence it is affects delivery of quality education for sustainable development. Social and economic activities limit parents and guardians to visit schools for student's academic purposes. However, in a family, parental involvement of Female is higher than that of male because women are not so busy like male.

Furthermore, the study discover that, those secondary schools implemented with web base education system, still rely on manual systems to execute their core function because of various reasons:

\section{i) Costs}

Due to budget constraints of Tanzanian secondary schools, most schools struggle to own Public IP address, powerful server machine and for employing IT professional system administrator.

\section{ii) Lack of system functionality}

The available system lacks system functionality that relates to the education system of Tanzania. A good example of this module for the system functionality is for calculating grade and division. The study discovers that, when the education system of Tanzania changed from one system to another system, the web based education system failed to adopt with new system of Tanzanian secondary schools.

\section{iii) Help Desk IT technical support}

Most private secondary schools bought the system from abroad. When it comes to a need of technical support, schools fail to get instant support from vendors because of distance apart. Lack of instant technical support from vendors lowers the work productivity of schools. The work productivity of teachers also used to be affected because they have to wait for technical support before they resume their activity.

\section{A. Proposed solution}

Due to dramatic change of technology, accurate, reliable and timely data remain a life line of all education stakeholders. Education policy makers require quality data to support their activities of formulating education policies [28]. This study solved a problem by developing and implementing a centralized Education Management Information System (EMIS) for allowing parents and guardians to track student's academic progress online rather than using manual system. The centralized system eliminates costs for secondary schools to own public IP address, powerful server machine and for employing a professional IT system administrator. Instead, the system will be hosted at central point of administration to ensure high dedicated Help Desk IT technical Support.

\section{B. Use case diagram}

The diagram below illustrates the use case diagram of the Education Management Information System. The system consists of five users who are systems administrator, teacher, student parent and Ward Education Coordinator (WEC). School academic teacher is given system administrative roles of managing the system. The system administrator has a read, write and execute access control. He / She can add users, add subjects, add class and assign subjects to the teacher. Teachers have read and write access control. They can upload results, print student's attendance and results. Parents and students can track academic progress by login and view student's attendance, student's behavior and results into the system. Fig. 8 below presents use case diagram of the EMIS.

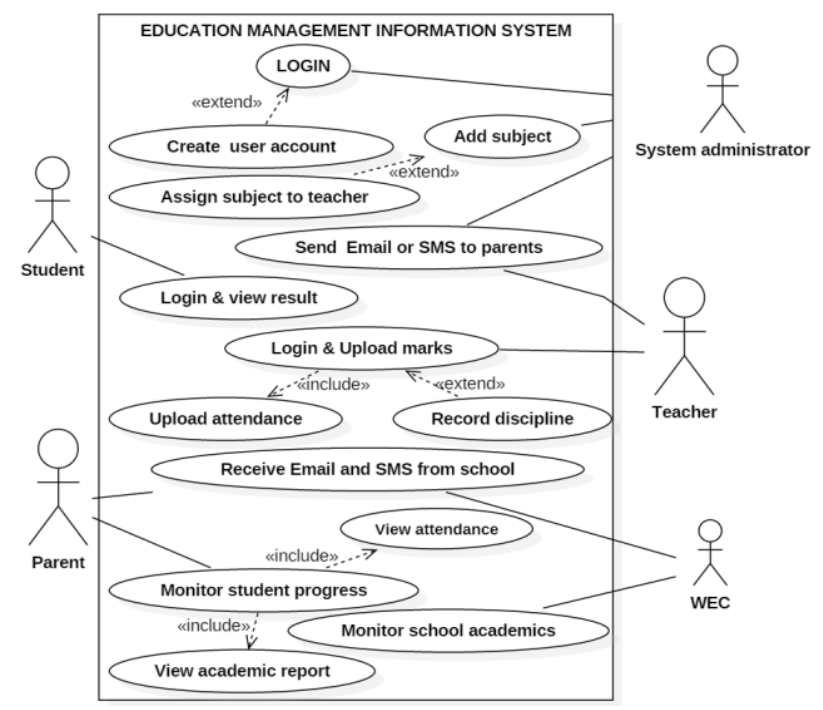

Fig.8. Use case diagram of the system 


\section{School academic teacher dashboard}

Due to school budget constraints, the Education Management Information System (EMIS) is designed for cost effective manner. However, the system does not require school to employ IT professional system administrator. Instead, the school academic teacher will be trained and given administrative tasks for controlling and managing the Education Management Information
System (EMIS). The core function of the school's academic teacher will be register system users and grant user access, add subjects, assign teacher a subject for teaching and other to perform other duties pertaining to his job responsibilities. Fig.9 below presents the dashboard showing tasks that are to be performed by the school academic teacher.

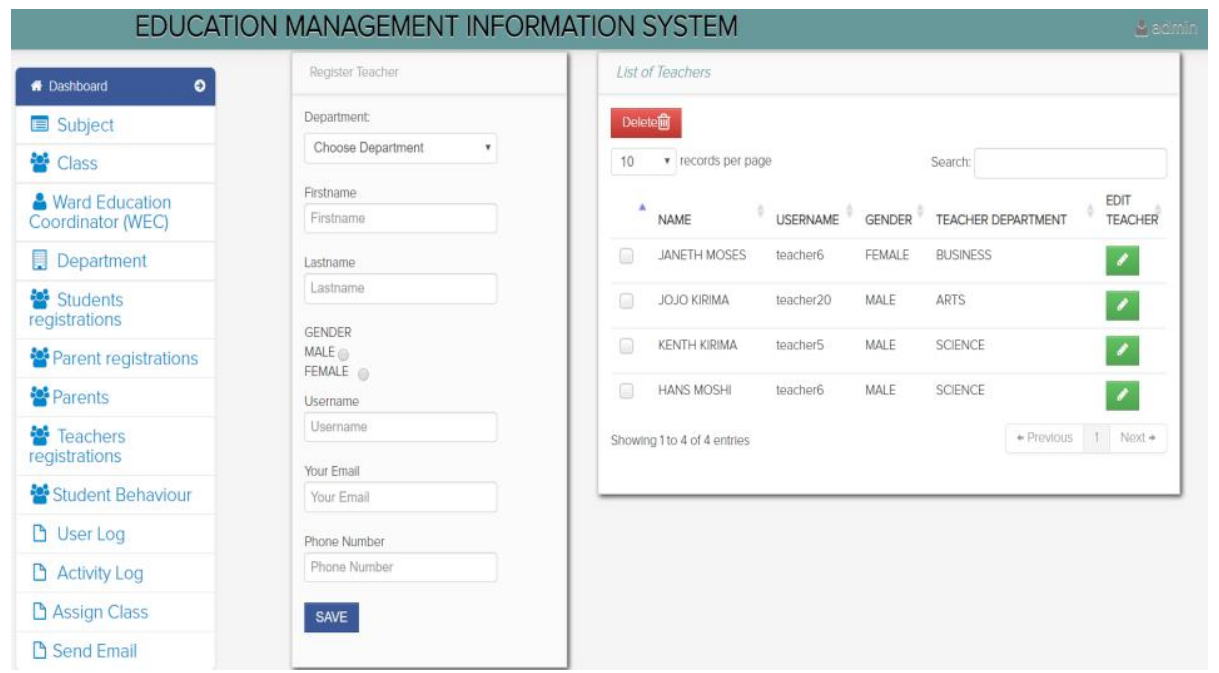

Fig.9. Dashboard for the school academic teacher

\section{Subject teacher dashboard}

The subject teacher can upload student's marks, attendance and the system will automatically generate a warning message to the parents when it happen the marks uploaded by the teacher is not under performance set by the school. Fig.10 below shows the system dashboard teacher dashboard

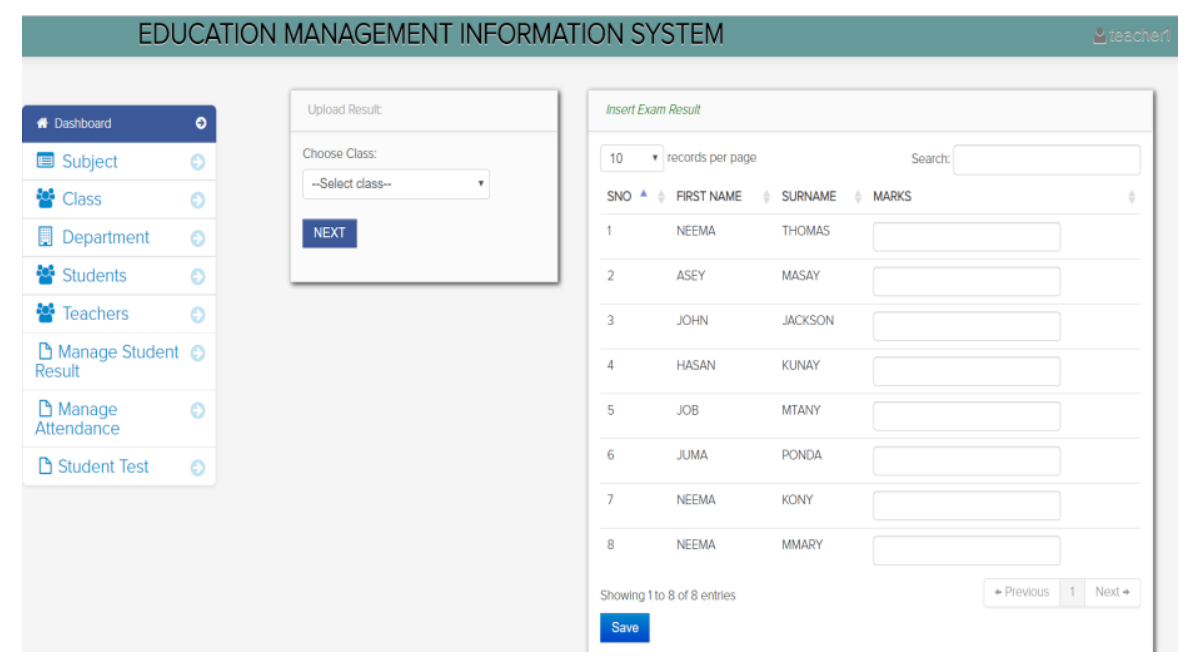

Fig.10. Dashboard of the teacher

\section{E. Parent dashboard for tracking student academic progress}

From the system, parent can login, view the class attendance of the student for each subject, marks scored and generate student's academic report. However, the parent will be sent with a warning message by the system before even login when it happen the marks scored by the student is bellow standard set by the school. Fig. 14 below shows parent dashboard for generating student's academic report. 


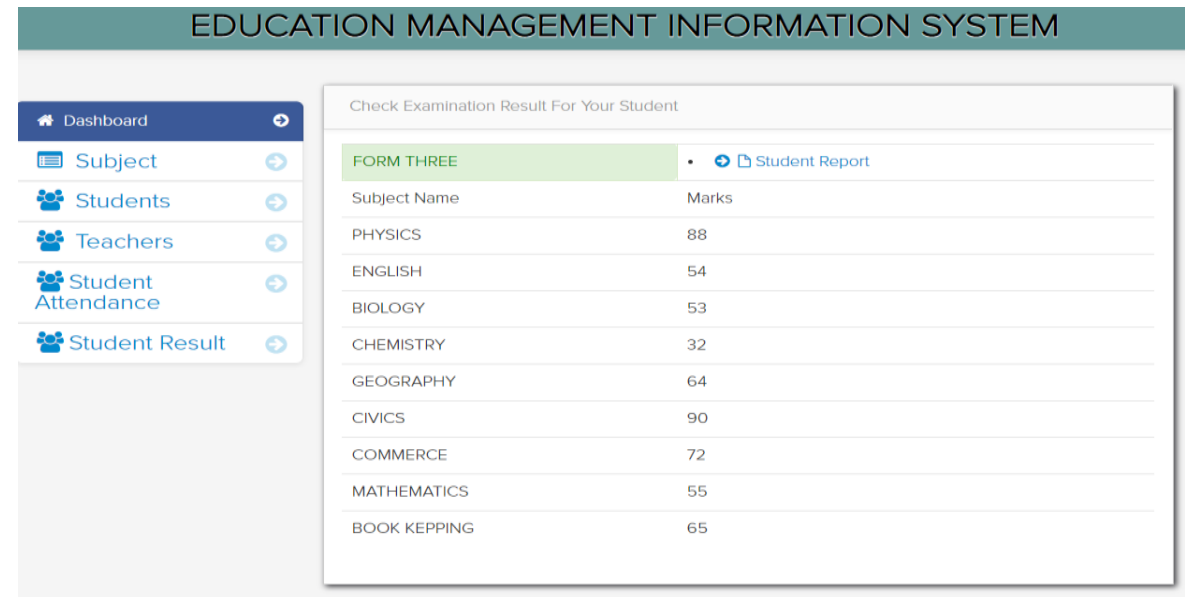

Fig.11. Dashboard for retrieving student's academic report

\section{CONCLUSION}

Despite of recognizing ICT as a pedagogical tool for teaching and learning processes, ICT can be well used in Tanzanian secondary schools to improve parental involvement for student academic achievement. However, application of using Centralized Education Management Information System (EMIS) for administering school academic activities is a vital practice of improving quality of education for sustainable development. Moreover, the study discovered that improving quality of education for sustainable development requires innovative ideas and collective knowledge from all school education stakeholders.

\section{REFERENCES}

[1] Lewin C, Luckin R. Computers \& Education Technology to support parental engagement in elementary education : Lessons learned from the UK. Comput Educ. 2018;54(3):749-58.

[2] Hornby G, Witte C. Parental involvement in secondary schools in New Zealand: Implications for school psychologists. 2017;

[3] MDEP. Education, Equitable access to excellent. 2017.

[4] Walker CN. Parents' and teachers' perspectives regarding parental involvement and student achievement [Internet]. 2017. Available from: http://scholarworks.waldenu.edu/dissertations

[5] Kimaro AR. Impacts of parental involvement in school activities on academic achievement of primary school children. 2015;3(8):483-94.

[6] Harris A, Goodall J. Engaging Parents in Raising Achievement- Do They Know They Matter? Univ Warwick. 2017;(July):1-93.

[7] Brown P. Involving Parents in the Education of Their Children. Ossc Bull. 2016;1-5.

[8] V.Nyembeke I. Parental involvement on student's academic activities. 2008. 2016;

[9] Goodall J, Brooks G, Akerman R. Review of best practice in parental engagement. Department of Education; 2016.

[10] Gu L. Using school websites for home - school communication and parental involvement? Nord J Stud Educ Policy [Internet]. 2017;3(2):133-43. Available from: https://doi.org/10.1080/20020317.2017.1338498
[11] Unesco. Education for Sustainable Development Goals. 2017.

[12] URT. Secondary Education Development Programme II (July 2010-June 2015). Vol. 7, Development. 2015.

[13] Olmstead BC, County O, Mesa C. Using Technology to increase Parental Involvement in schools. 2015; Available from: http://www.techtrends.com

[14] Beasley AP. Administrators Using Technology to Increase Family Engagement. 2015; Available from: http://digitalcommons.kennesaw.edu/instruceddoc_etd

[15] Wong-villacres M, Litoral P, Solomon A, Disalvo B, Buil MP. Design Guidelines for Parent-School Technologies to Support the Ecology of Parental Engagement. 2017;

[16] Cheairs SE. Perceptions of Parental Involvement Among Rural Parents, Teachers, and Administrators. 2015;

[17] Cheng Y, Chen Y. Enhancing classroom management through parental involvement by using social networking apps. South African J Educ. 2019;38(Supplement 2):1-14.

[18] Lewin C, Luckin R. Computers \& Education Technology to support parental engagement in elementary education : Lessons learned from the UK. Comput Educ [Internet]. 2010;54(3):749-58. Available from: http://dx.doi.org/10.1016/j.compedu.2009.08.010

[19] Becta. Exploiting ICT to imrpove parental engagement, movng towards online repoting 01 [Internet]. 2008. Available from: http://www.becta.org.uk

[20] Akter AHK and F. Parental Involvement in the Secondary Schools in Bangladesh: Challenges and a Way Forward. 2014;10(1):1-18.

[21] Makokha MM, Raburu P, Mary A. Effects of Parental Monitoring On Academic Achievement of Secondary School Students in Busia Sub-County , Busia County , Kenya. 2018;23(3):7-14.

[22] Olmstead BC, County O, Mesa C. Using Technology to increase parental involvement in schools. Vol. 57. 2015.

[23] Kemp J. Increasing Parent Involvement by Using a Variety of Communication Tools. 2015;

[24] Kraft MA, Dougherty SM. The Effect of Teacher-Family Communication on Student Engagement: Evidence from a Randomized Field Experiment Matthew. 2017;

[25] Chena ZX, Chena CC. The intention of using smart device messages as parent-teacher communication from the view of parents. Procedia Manuf [Internet]. 2015;3(Ahfe):5617-23. Available from: http://dx.doi.org/10.1016/j.promfg.2015.07.755

[26] Pingo. Social and economic contribution of Pastoralism as livehood in Tanzania. 2016.

[27] Sommerville I. Software Engineering. 2011. 
[28] Luena AM. Strengthening the Education Management Information System (EMIS) [Internet]. 2012. Available from: https://scholarworks.umass.edu/cie_capstones/21

\section{Authors' Profiles}

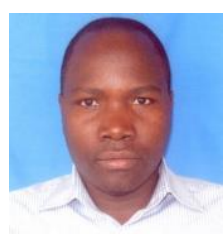

ANOLD S. NKATA is ICT Instructor at Arusha Technical College, Tanzania. He received BSc in Computer Science in 2008 from the Institute of Accountancy Arusha, Tanzania. He also pursued his Postgraduate Diploma in Computing (PGDC) in 2013 at the Institute of Accountancy Arusha, Tanzania. Currently he is doing MSc in Information Communication System Engineering (ICSE) at the Nelson Mandela African Institution of Science and Technology, Arusha-Tanzania. His research interest is on improving quality of education for sustainable development using digital technology for developing countries including Tanzania.

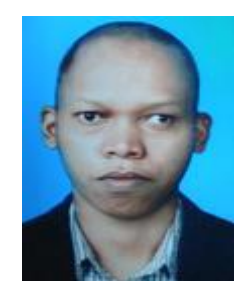

Dr. MUSSA A. DIDA is a Lecturer at the Nelson Mandela African Institution of Science and Technology (NM-AIST) Arusha, Tanzania. He received his $\mathrm{PhD}$ in Information and Communication Engineering in 2017 from Beijing Institute of Technology in China. He also completed $\mathrm{BSc}$ in Computer Engineering and Information Technology from University of Dar es Salaam in 2008 and his MSc in Telecommunication Engineering from the University of Dodoma in 2011. His research interest is on analyzing digital signal communication systems, system modeling, optimization, and on development of online systems. Currently he is working on farmer's extension support system and Tanzanian private secondary schools enrollment communication systems.

How to cite this paper: ANOLD S. NKATA, MUSSA A. DIDA, " Centralized Education Management Information System for Tracking Student's Academic Progress in Tanzanian Secondary Schools", International Journal of Modern Education and Computer Science(IJMECS), Vol.11, No.10, pp. 25-32, 2019.DOI: 10.5815/ijmecs.2019.10.03 